\title{
Antimicrobial alumina nanobiostructures of disulfide- and triazole-linked peptides: Synthesis, characterization, membrane interactions and biological activity
}

\author{
L.M.F.C. Torres ${ }^{a}$, M.T. Almeida ${ }^{a}$, T.L. Santos ${ }^{a}$, L.E.S. Marinho ${ }^{a}$, J.P. de Mesquita ${ }^{a}$, L.M. da Silva ${ }^{a}$, \\ W.T.P. dos Santos ${ }^{\mathrm{b}}$, H.R. Martins ${ }^{\mathrm{b}}$, K.C. Kato ${ }^{\mathrm{b}}$, E.S.F. Alves ${ }^{\mathrm{c}}$, L.M. Liao ${ }^{\mathrm{c}}$, M.T.Q. de Magalhães ${ }^{\mathrm{d}}$, \\ F.G. de Mendonça ${ }^{e}$, F.V. Pereira ${ }^{e}$, J.M. Resende ${ }^{e}$, M.P. Bemquerer ${ }^{f}$, M.A. Rodrigues ${ }^{g}$, R.M. Verly $^{\mathrm{a}, *}$ \\ ${ }^{a}$ Departamento de Química, Universidade Federal dos Vales do Jequitinhonha e Mucuri, 39100-000, Diamantina, MG, Brazil \\ ${ }^{\mathrm{b}}$ Faculdade de Farmácia, Universidade Federal dos Vales do Jequitinhonha e Mucuri, 39100-000. Diamantina, MG, Brazil \\ ${ }^{\mathrm{c}}$ Instituto de Química - Universidade Federal de Goiás, 74690-900 Goiânia - GO - Brazil \\ ${ }^{\mathrm{d}}$ Departamento de Bioquimica e Imunologia, Univesidade Federal de Minas Gerais, Av. Antônio Carlos, 6627, Pampulha, Belo Horizonte, MG, CEP 31270-901, Brazil

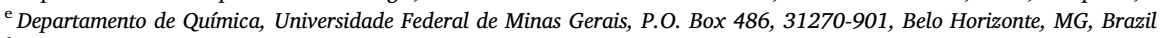 \\ ${ }^{\mathrm{f}}$ Embrapa Recursos Genéticos e Biotecnologia, Parque Estação Biológica, PqEB, Av. W5 Norte (final), P.O. Box 02372, Brasília, DF, Brazil \\ ${ }^{\mathrm{g}}$ Departamento de Bioquímica, Instituto de Química, Universidade de São Paulo, 05508-000, São Paulo, SP, Brazil
}

\section{A R T I C L E I N F O}

\section{Keywords:}

Nanobiomaterials

Peptide-decorated alumina nanoparticles

Alumina nanoparticles

Antimicrobial peptides

Peptide synthesis

Antifungal activity

Antibacterial activity

Copper(I)-catalyzed cycloaddition reaction

\begin{abstract}
A B S T R A C T
Due to the its physical-chemical properties, alumina nanoparticles have potential applications in several areas, such as nanobiomaterials for medicinal or orthodontic implants, although the introduction of these devices poses a serious risk of microbial infection. One convenient strategy to circumvent this problem is to associate the nanomaterials to antimicrobial peptides with broad-spectrum of activities. In this study we present two novel synthesis approaches to obtain fibrous type alumina nanoparticles covalently bound to antimicrobial peptides. In the first strategy, thiol functionalized alumina nanoparticles were linked via disulfide bond formation to a cysteine residue of an analog of the peptide BP100 containing a four amino acid spacer (Cys-Ala-Ala-Ala). In the second strategy, alumina nanoparticles were functionalized with azide groups and then bound to alkyne-decorated analogs of the peptides BP100 and DD K through a triazole linkage obtained via a copper(I)-catalyzed cycloaddition reaction. The complete physical-chemical characterization of the intermediates and final materials is presented along with in vitro biological assays and membrane interaction studies, which confirmed the activity of the obtained nanobiostructures against both bacteria and fungi. To our knowledge, this is the first report of aluminum nanoparticles covalently bound to triazole-peptides and to a disulfide bound antimicrobial peptide with high potential for biotechnological applications.
\end{abstract}

\section{Introduction}

Nanoparticle research is of interest to large community of scientists due to its wide variety of applications in different biotechnological fields. In the current medical scenario, these innovative technologies allow to build a range of original products that can profoundly influence and improve human health in the context of both treatment and in monitoring therapies $[1,2]$. Some physical-chemical properties of nanobiostructures, such as increased surface-to-volume ratio, effects of shape and size on function, and formation of chemically controlled selfassembled nanobiostructures impart applications in health, food and agricultural sciences [3-5]. In addition, the increase in microbial resistance has boosted research and applications of nanoparticles conjugated with biomolecules expanding to field of nano-sized antiseptic biomaterials [6-8].

Nanophase alumina has been widely used in both dental and orthopedic implant fields by regulating the activity of bone cells, especially by increasing the adhesion and the proliferation of osteoblasts on the surface of nanofibrous alumina [8-11]. Nevertheless, there is a serious risk of microbial infection following the insertion of these devices and in this context the use of antimicrobial peptides has proven to be an excellent alternative to conventional antibiotics in view that these molecules show low side effects and that they usually do not induce antimicrobial resistance due to their specificity of interaction with the

\footnotetext{
* Corresponding author.

E-mail address: verly.rodrigo@ufvjm.edu.br (R.M. Verly).
} 
bacterial membrane [12,13]. Therefore, the development of hybrid ceramic nanoparticles, as alumina containing antimicrobial peptides, may prove to be a convenient strategy to avoid infection and rejection of orthodontic or orthopedic implants. Although the coupling of peptides to alumina nanoparticles seems to represent an excellent advantage in materials used as medical devices, little attention has been given to these promising nanobiomaterials. It was only recently shown that a peptide-alumina nanoparticle conjugate can be highly effective for the treatment of some biological conditions, such as allergic asthma in rats [14]. Very recently, our team proved the antimicrobial potential of nanofibrous alumina covalently bound to the antimicrobial peptide BP100 in assays against Escherichia coli and Salmonella typhimurium strains [15]. These results indicated that peptide-decorated nanobiostructures may present important applications in food packaging in order to avoid microbial contamination and improve food shelf-life $[16,17]$.

Despite the advantages of these materials, the low functionalization degree of alumina with peptides by amide bond formation hampers the synthesis of these nanobiostructures. In this context we propose here two novel synthesis approaches to obtain fibrous-like alumina nanoparticles covalently bound to antimicrobial peptides. The first strategy consists in the functionalization of both, alumina nanoparticles and an analog of BP100 containing a three-alanine spacer at the $N$-terminus, with a cysteine residue (CAAAKKLFKKILKYL- $\mathrm{NH}_{2}$ ), which allows disulfide bond formation. The second strategy consists in connecting the BP100 and DD K peptide structures to the nanoparticle surface via a copper(I)-catalyzed azide alkyne cycloaddition reaction (CuAAC). Alkyne-decorated peptides were obtained by incorporating a propargylglycine (2-aminopent-4-ynoic acid, [Pra]G) residue in the sequences of the BP100 analog ([Pra]GAAAKKLFKKILKYL- $\mathrm{NH}_{2}$ and DD $\mathrm{K}$ (GLWSKIKAAGKEAAKAAAK AAGKAALNAVSEAV[Pra]G-NH ${ }_{2}$ ) during the peptide syntheses, whereas the nanoparticle surface was functionalized with azide groups. The CuAAC reaction results in a triazole linkage between the nanoparticle and the peptide moiety, which is of great biological interest, since azoles are known to effectively inhibit fungal growth and development [18]. Therefore, the CuAAC reaction leads to a nanoparticle-triazole-peptide (NP-TP) conjugates, even for long peptide chain as DD K, which have potential applications against fungal pathogens. Besides presenting the synthesis and physical-chemical characterization of the obtained nanoparticles, we show here investigations of their membrane interactions along with their antimicrobial activities. To analyze the effect of the peptide-nanoparticle conjugation on the activity of the nanobiostructures, the individual species, namely, peptides, triazole-peptides and alumina nanoparticles were also prepared and submitted to similar biophysical and activity studies.

\section{Experimental section}

\subsection{Materials}

Details of materials used in all experiments and most of the experimental procedures can be found in the Supplementary material (SM).

\subsection{Peptide synthesis}

Manual solid phase peptide synthesis (SPPS) was employed to obtain the peptide sequences by using the Fmoc (9-fluorenylmethoxycarbonyl) strategy [19]. All details can be found in the SM.

\subsection{Preparation of the alumina nanoparticles and derivatives forms}

The method for obtaining the alumina nanoparticles was based on a protocol described in the literature with some modifications [20]. The functionalization steps and obtaining the derivatives forms, including disulfide-linked peptide-alumina nanoparticle (route 1) and triazolelinked peptide-alumina nanoparticle (route 2) are described in detail in the SM.

\subsubsection{Substitution degrees of the NP-(Fmoc)peptides and NP-(Fmoc) triazole-peptides}

The substitution degrees of the amidated alumina nanoparticles immobilized with Fmoc-Cys(Trt)-OH, Fmoc-peptides and Fmoc-triazole-peptides were achieved by Fmoc quantification, after the final $\mathrm{N}$ terminus deprotection. See details in SM.

\subsection{Characterization}

\subsubsection{Physical characterization}

2.4.1.1. Powder X-ray diffraction (XRD) analysis. The crystalline structure of the alumina nanoparticles and of their derivatives were analyzed by XRD using a DRX6000 diffractometer (Shimadzu, Kyoto, Japan) with $\mathrm{Cu} \mathrm{K \alpha}$ radiation $(\lambda=1.540560 \AA)$ at $200 \mathrm{~mA}$ and $40 \mathrm{kV}$. Silicon was used as an external standard. The Rietveld structural refinement of the XRD data was performed with the software FullProf_Suite 2015.

2.4.1.2. Transmission Electron Microscopy (TEM). Transmission electron microscopy (TEM) and high resolution transmission electron microscopy (HRTEM) images of the of the nanoparticles before and after immobilization of the peptides and triazole-peptides were obtained on a Tecnai G2-20 - SuperTwin FEI - $200 \mathrm{kV}$ (FEI Company, Hillsboro, OR, USA) microscope at an acceleration voltage of $200 \mathrm{kV}$. The sample suspensions were deposited on a holey-carbon electron microscopy grid.

2.4.1.3. Thermal analysis. The mass losses of the NP, NP-OH, NP- $\mathrm{NH}_{2}$, NP-Cl, NP-N ${ }_{3}$, NP-Cys, NP-CAAA-BP100, NP-[Trz- $\beta$-A $\left.{ }^{1}\right]$ AAA-BP100 and NP-[Trz- $\left.\beta-A^{34}\right]$-DD $K$ samples were investigated on a DTG $60 \mathrm{H}$ equipment (Shimadzu, Kyoto, Japan). The analyses were carried out using an alumina sample holder under inert $\mathrm{N}_{2}$ atmosphere (flow of $50 \mathrm{~mL} \cdot \mathrm{min}^{-1}$ ). The analyses were performed from 30 to $600{ }^{\circ} \mathrm{C}$ with a heating rate of $10^{\circ} \mathrm{C} \cdot \mathrm{min}^{-1}$.

\subsubsection{Structural characterization}

2.4.2.1. Fourier transform infrared spectroscopy. In order to characterize the products obtained after each functionalization step, the infrared spectra of NP, NP-OH, NP-NH $\mathrm{N}_{2}, \mathrm{NP}-\mathrm{Cl}, \mathrm{NP}-\mathrm{N}_{3}, \mathrm{NP}-\mathrm{Cys}$, NP-CAAABP100, NP-[Trz- $\left.\beta-A^{1}\right]$ AAA-BP100, NP-[Trz- $\beta$ - $\left.A^{34}\right]$-DD K, CAAA-BP100, [Trz- $\beta$ - $\left.\mathrm{A}^{1}\right]$ AAA-BP100, and [Trz- $\left.\beta-\mathrm{A}^{34}\right]$-DD $\mathrm{K}$ were recorded on a Varian 640-IR FT-IR spectrophotometer (Santa Clara, CA, USA) equipped with attenuated total reflectance accessory (ATR, Pike Technologies, GladiATR model). The spectra were recorded in the 4000 to $400 \mathrm{~cm}^{-1}$ region, with $8 \mathrm{~cm}^{-1}$ resolution and 32 accumulations.

2.4.2.2. Solid-state nuclear magnetic resonance (ssNMR) spectroscopy. Structure characterization was also performed by using Proton-decoupled ${ }^{13} \mathrm{C}$ solid-state NMR spectra were recorded at $306 \mathrm{~K}$ on a Bruker Avance III 500 (11.75 T) spectrometer (Bruker BioSpin, Karlsruhe, Germany) equipped with a $4 \mathrm{~mm} \mathrm{CP} / \mathrm{MAS}$ probe. All details are described in the SM.

\subsection{Biophysical experiments}

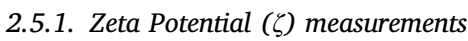

Zeta potential measurements were conducted on a Zeta ${ }^{\circledast}$ Nano $\mathrm{ZS}^{\circledast}$ particle analyzer from Malvern Instrument Ltd (Worcestershire, UK). Details are described in the SM.

\subsubsection{Circular dichroism (CD) spectroscopy}

Circular dichroism spectra were recorded using a JASCO J-815 
spectrometer (Easton, MD, USA) coupled to a Peltier Jasco model PTC$423 \mathrm{~L}$ temperature control system, using a quartz cuvette with $1 \mathrm{~mm}$ optical path. Details can be found in the SM.

\subsubsection{Surface plasmon resonance (SPR)}

SPR measurements were performed at $670 \mathrm{~nm}$ with a flow rate of $50 \mathrm{~mL} \cdot \mathrm{min}^{-1}$ on a Multi-Parametric Surface Plasmon Resonance (MPSPR) instrument SPRNavi 200 (BioNavis ${ }^{\circledR}$, Ylöjärvi, Finland). The experiments were carried out at $25^{\circ} \mathrm{C}$ employing $\mathrm{SiO}_{2} \mathrm{SPR}$ sensor chips (SPR102-SiO ${ }_{2}$ ) and the flow rate for LUV immobilization and for peptide injection was $50 \mu \mathrm{L} \mathrm{min}{ }^{-1}$. All details are described in the SM.

\subsection{Antimicrobial activity assay}

Antibacterial and antifungal actions of NP, NP-OH, NP-NH $2, \mathrm{NP}-\mathrm{Cl}$, NP-N ${ }_{3}$, NP-Cys, NP-CAAA-BP100, NP-[Trz- $\beta$ - A $^{1}$ ]AAA-BP100, NP-[Trz- $\beta$ $\mathrm{A}^{34}$ ]-DD $\mathrm{K}$, free peptides BP100, CAAA-BP100, and free triazole-peptides $\left[\right.$ Trz- $\beta$ - $\left.A^{1}\right]$ AAA-BP100 and $\left[\right.$ Trz- $\beta$ - A $\left.^{34}\right]$-DD $K$ were investigated on three bacterial and two yeast strains. Details of antibacterial and antifungal assays can be found in the SM.

\section{Results}

\subsection{Synthesis of the triazole-peptide nanobiostructures}

All the peptides were obtained by SPPS and the two triazole-peptides by SPPS followed by CuAAC reaction in the presence of sodium azide. The products were purified by reverse-phase HPLC and characterized by mass spectrometry (Figure S1, Supporting information).

The synthetic routes used to prepare the peptide-decorated and the triazole-peptide-decorated alumina nanoparticles (NP-CAAA-BP100, NP- $\left[\right.$ Trz- $\beta$-A $\left.{ }^{1}\right]$ AAA-BP100 and NP- $\left[\right.$ Trz- $\left.\beta-A^{34}\right]$ DD K) are presented in Fig. 1.

\subsubsection{NP-CAAA-BP100 (Route 1)}

In Route 1, hydroxylated alumina (NP-OH) was reacted with APTES to produce the aminated nanoparticles $\left(\mathrm{NP}-\mathrm{NH}_{2}\right)$, which were coupled to pre-activated Fmoc-Cys(Trt)-OH benzotriazole active ester. After two deprotection steps, the cysteine derivative (NP-Cys), which carries a free thiol group on the nanoparticle surface, was obtained. The functionalization degree of the nanostructures covalently bound to a cysteine residue was determined as $0.21 \mathrm{mmol} . \mathrm{g}^{-1}$. The NP-CAAA-BP100 nanobiostructures were obtained by reacting the free peptide CAAABP100 with NP-Cys in slightly alkaline medium to allow the formation of a disulfide bond. Compared with the functionalization degree of NPCys $\left(0.21 \mathrm{mmol} . \mathrm{g}^{-1}\right)$, the degree of CAAA-BP100 immobilization is significantly lower $\left(0.02 \mathrm{mmol}^{-1}\right)$.

\subsection{2. $N P-\left[T r z-\beta-A^{1}\right] A A A-B P 100$ and $N P-\left[T r z-\beta-A^{34}\right]-D D K$ (Route 2)}

In this synthetic route the APTES coupling to the NP-OH was replaced by the reaction with 3-chloropropyl(triethoxy)silane (CPTES), which was however performed under very similar conditions. The presence of chlorine atoms in the nanostructure (NP-Cl) is necessary to introduce the azide group on the nanoparticle surface (NP- $\left.\mathrm{N}_{3}\right)$ through a nucleophilic substitution reaction. Finally, NP-[Trz- $\beta$ - A $\left.^{1}\right]$ AAA-BP100 was obtained by the 1,3-dipolar cycloaddition reaction between $\mathrm{NP}-\mathrm{N}_{3}$ and [Pra]GAAA-BP100 under $\mathrm{Cu}(\mathrm{I})$ catalysis. The quantification of peptide molecules immobilized on the alumina nanoparticles was performed as previously described for the NP-CAAA-BP100. A functionalization degree of $0.07 \mathrm{mmol} . \mathrm{g}^{-1}$ was determined for NP-[Trz- $\beta$ $\mathrm{A}^{1}$ ]AAA-BP100. Similarly, NP-[Trz- $\left.\beta-\mathrm{A}^{34}\right]$-DD $\mathrm{K}$ was obtained using $\left[\mathrm{Pra}_{\mathrm{G}} \mathrm{G}^{34}\right.$-DD $\mathrm{K}$ and a functionalization degree of $0.02 \mathrm{mmol}^{-1} \mathrm{~g}^{-1}$ was obtained.

\subsection{Characterization of the alumina nanoparticles}

$X R D, T E M$ and HRTEM - According to the qualitative analysis of the XRD patterns [15]. the synthesized nanoparticles obtained before functionalization with peptides (NP, NP-OH, NP- $\mathrm{NH}_{2}, \mathrm{NP}-\mathrm{Cys}, \mathrm{NP}-\mathrm{Cl}$, and NP- $\mathrm{N}_{3}$ ) consist of a single phase corresponding to a cubic structure of $\gamma-\mathrm{Al}_{2} \mathrm{O}_{3}$ ( $F d-3 \mathrm{~m}$, Figure S2) [21].

The TEM and HRTEM images collected for the alumina nanoparticles (NP) and peptide- and triazol-peptide-decorated alumina nanoparticles are shown in Fig. 2. The NP sample has a predominantly fibrous morphology with diameters around $5 \mathrm{~nm}$ and lengths smaller than $100 \mathrm{~nm}$ (Fig. 2A). High resolution images of this sample clearly show the presence of different crystalline planes. The interlayer distances of the highlighted regions in Fig. 2B (1 and 2) and Fig. 2C (3) are $0.20,0.24$ and $0.42 \mathrm{~nm}$ (respectively). Selected area electron diffraction (SAED) reveals well-crystalized $\mathrm{Al}_{2} \mathrm{O}_{3}$ phase (inset in Fig. 2B) with the presence of 311, 400 and 440 planes [22], which is in agreement with the observed interplanar distances. These results confirm that the obtained $\mathrm{Al}_{2} \mathrm{O}_{3}$ nanostructures have well-defined morphology and crystal structure. In general, the functionalization with the peptides did not alter the fibrous morphology of the nanostructures. NP-CAAA-BP100, NP-[Trz- $\beta$-A $\left.{ }^{1}\right]$ AAA-BP100 and NP-[Trz- $\left.\beta-A^{34}\right]$-DD K images (Fig. 2D-I) were similar in shape and size to those of the unmodified NP (Fig. 2A-C). However, an analysis of several regions clearly show that the peptide-decorated nanostructures show a higher agglomeration degree.

\subsection{Spectroscopic characterization}

\subsubsection{Fourier transform infrared spectroscopy}

Fig. 3 shows the FTIR spectra collected for all alumina nanoparticles and free peptides. In the NP spectrum (Fig. 3a), a large band at 400$800 \mathrm{~cm}^{-1}$ is consistent with characteristic vibrations of aluminum oxide at $621 \mathrm{~cm}^{-1}(\nu \mathrm{Al}-\mathrm{O})$ and $474 \mathrm{~cm}^{-1}(\delta \mathrm{Al}-\mathrm{O})$. [23] Similar bands were observed for all nanoparticles (peptide-functionalized or not), resulting in a characteristic profile of the inorganic material in the respective spectra (Fig. 3a-i).

A broad band between 3690 and $3000 \mathrm{~cm}^{-1}$ was observed in the NP-OH spectrum (Fig. 3b) and attributed to stretching of hydrogenbonded O-H groups [24]. In the NP- $\mathrm{NH}_{2}$ spectrum (Fig. 3c), two bands between 3000 and $2900 \mathrm{~cm}^{-1}$ are related to the $\mathrm{C}-\mathrm{H}$ stretchings, caused by the immobilization of a propyl organic group containing a primary amine. Following the functionalization steps for CAAA-BP100 peptide immobilization on the nanoparticle surface, characteristic vibrations of cysteine residues (weak S-H stretch near $2550 \mathrm{~cm}^{-1}$ ) and amide bonds were observed for NP-Cys (carboxamide linkage to the nanoparticle, amide I band near $1650 \mathrm{~cm}^{-1}$ ) and NP-CAAA-BP100 (Fig. 3a and g). Thus, stretching of the $\mathrm{C}=\mathrm{O}$ bonds (at $1650 \mathrm{~cm}^{-1}$ ), symmetrical angular strain of $\mathrm{N}-\mathrm{H}$ bonds (between 1200 and $1120 \mathrm{~cm}^{-1}$ ) and $\mathrm{N}-\mathrm{H}$ (near $3300 \mathrm{~cm}^{-1}$ ) and $\mathrm{C}-\mathrm{H}$ stretchings (between 3000 and $2900 \mathrm{~cm}^{-1}$ ) are identified in both spectra. Similar vibrations were also visualized in the spectrum of the non-immobilized CAAABP100 peptide (Fig. 3j), confirming the functionalization of the nanoparticles.

Following the route to obtain the NP-triazole-peptides (Route 2), in the IR spectrum of NP-Cl (Fig. 3e) the $\mathrm{C}-\mathrm{H}$ stretchings were observed near $3000 \mathrm{~cm}^{-1}$, together with the characteristic low intensity folding band of $\mathrm{CH}_{2}-\mathrm{Cl}$ at $1300-1230 \mathrm{~cm}^{-1}$, which confirms the immobilization of the chloroalkylsilyl group. In the spectrum of NP-N $\mathrm{N}_{3}$ (Fig. 3f), the $\mathrm{C}-\mathrm{N}$ stretch band occurs in the range of $1350-1000 \mathrm{~cm}^{-1}$. In the spectrum of the NP-triazole-peptides (Fig. 3k-1) bands related to the deformation of $\mathrm{C}=\mathrm{O}$ bonds, symmetrical angular strain of $\mathrm{N}-\mathrm{H}$ bonds and $\mathrm{N}-\mathrm{H}$ and $\mathrm{C}-\mathrm{H}$ stretchings are observed.

3.3.2. ssNMR chemical shift assignments

In order to obtain detailed information about the chemical 


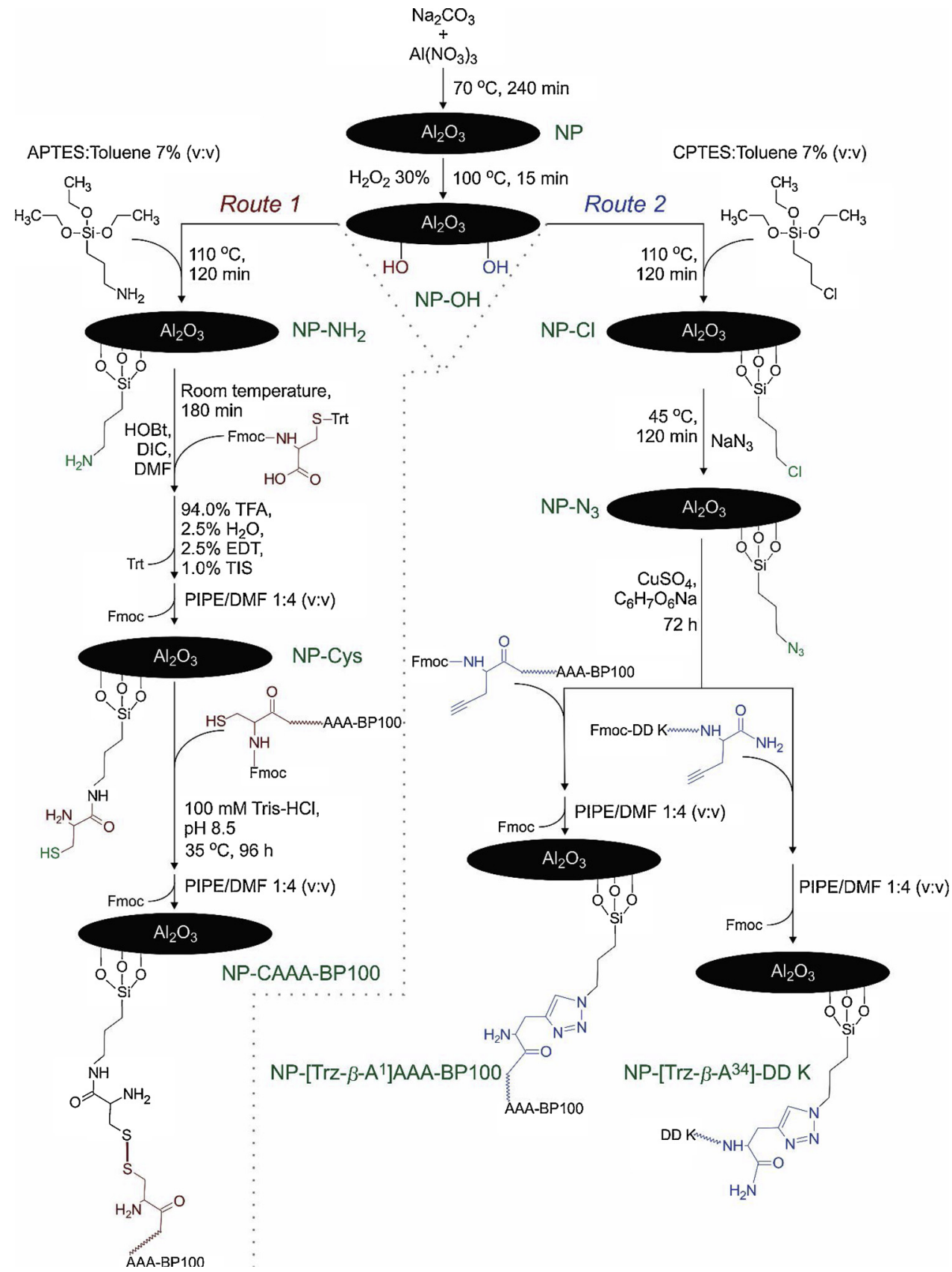

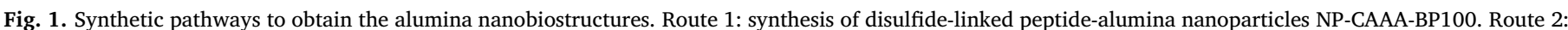
synthesis of triazole-linked peptide-alumina nanoparticles NP-[Trz- $\beta$-A $\left.{ }^{1}\right]$ AAA-BP100 and NP-[Trz- $\beta$-A $\left.{ }^{34}\right]-D D$ K.

structures of the synthesized nanoparticles, solid-state ${ }^{13} \mathrm{C}$ NMR spectra of the free peptides and of all alumina nanoparticles were recorded (Fig. 4). As expected, no ${ }^{13} \mathrm{C}$ resonance signals were observed for the NP and $\mathrm{NP}-\mathrm{OH}$ inorganic nanoparticles (Fig. $4 \mathrm{a}$, and b), indicating that these materials are not contaminated with organic molecules. Interestingly, intense ${ }^{13} \mathrm{C}$ resonances were observed between 0 and $50 \mathrm{ppm}$ in the spectra of NP-NH $2, \mathrm{NP}-\mathrm{Cl}$ and NP-N $\mathrm{N}_{3}$, which is consistent with the saturated ethoxy $\left(\mathrm{C}_{\alpha}, \mathrm{C}_{\beta}\right.$ and $\mathrm{C}_{\gamma}$ silane carbons) and aminoalkylsilyl / chloroalkylsilyl / azidoalkylsilyl groups of these nanoparticles (Fig. 4c, e, and f).

With regard to the synthesis of the disulfide-linked alumina-peptide (route 1) unequivocal ${ }^{13} \mathrm{C}$ chemical shifts of Cys residue at $57 \mathrm{ppm}$, $30.9 \mathrm{ppm}$ and $164.2 \mathrm{ppm}$ were attributed to the $\mathrm{C}_{\alpha}, \mathrm{C}_{\beta}$ (thiol carbon) and carboxamide carbon, respectively, for the NP-Cys (Fig. 4d). Typical ${ }^{13} \mathrm{C}$ chemical shifts of side chains, $\mathrm{C}_{\alpha}$ and carboxamide were observed in the spectra of free CAAA-BP100 (Fig. 4k) and of NP-CAAA-BP100 (Fig. 41). An intense signal at $38 \mathrm{ppm}$, which corresponds to the resonance of $\mathrm{C}_{\beta}$ of the cystine residue, confirms that most of the original thiol groups of the cysteine residues (observed at $30.9 \mathrm{ppm}$ either for NP-Cys or for CAAA-BP100) were oxidized, resulting in the disulfide bond formation (Fig. 41) [25-27].

Regarding the syntheses of the triazole-peptide-decorated nanoparticles (route 2), the spectra of the free triazole-peptides (Fig. 4g, i) and NP-triazole-peptides (Fig. 4h, j) show chemical shift ranges characteristics of $\mathrm{C}_{\alpha}(50-60 \mathrm{ppm})$ and aliphatic (10-30 ppm) side chains. The spectra of the free triazole-peptides (Fig. $4 \mathrm{~g}$, i) and NP-triazolepeptides (Fig. 4h, j) show chemical shift ranges characteristic of the peptide structures. It is worth to highlight the presence of two ${ }^{13} \mathrm{C}$ chemical shifts of the triazole carbon resonances between 114 and $134 \mathrm{ppm}$ in the spectra of the NP-[Trz- $\left.\beta-\mathrm{A}^{1}\right]$ AAA-BP100 and NP-[Trz- $\beta$ - 

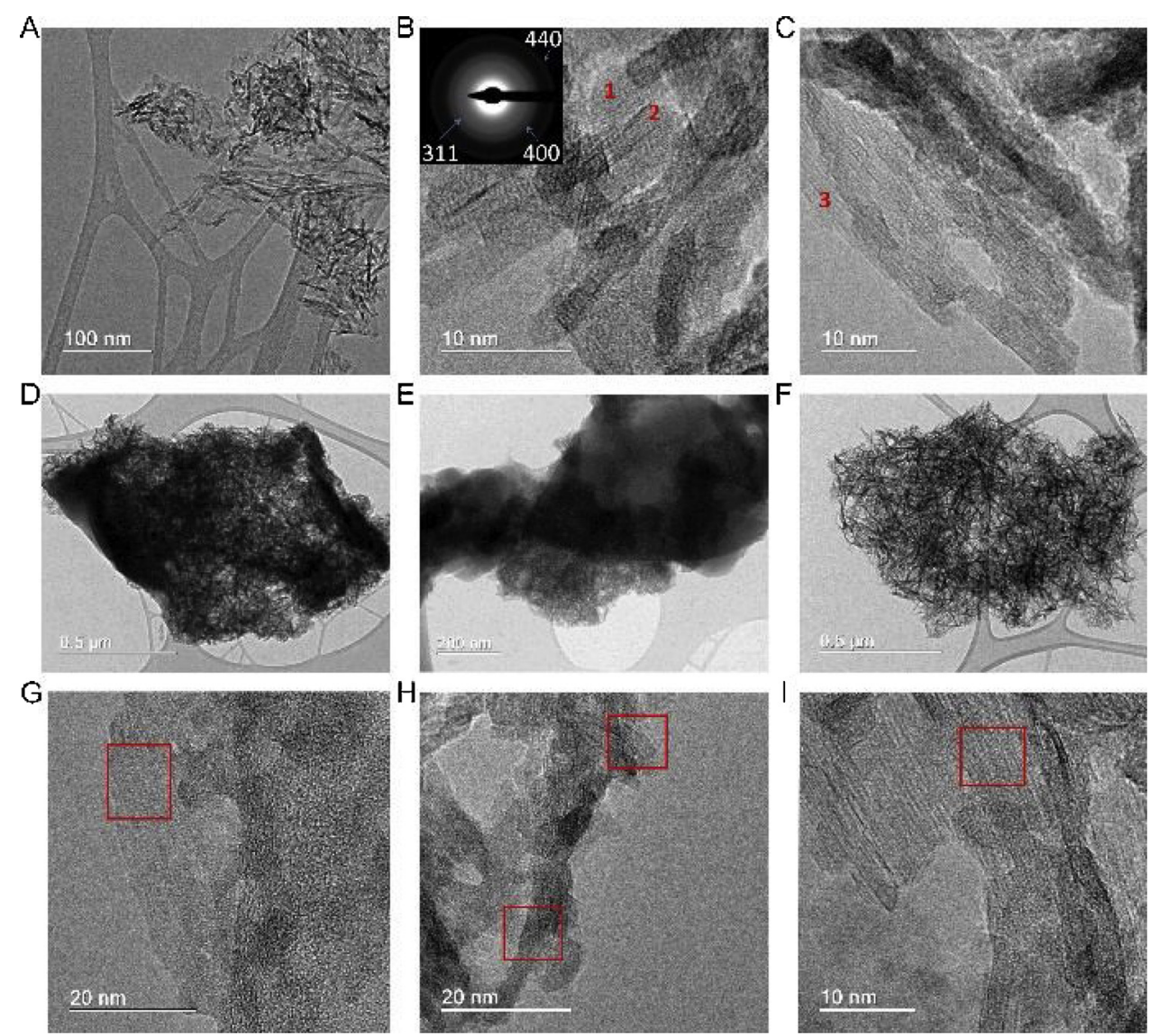

Fig. 2. TEM and HRTEM images obtained for nanoparticles. (A, B, and C) Unmodified NP. Inset: electron diffraction pattern of the corresponding selected area for $\gamma$ $\mathrm{Al}_{2} \mathrm{O}_{3}$ NP. Functionalized NP: (D and G) NP-CAAA-BP100; (E and H) NP-[Trz- $\beta$-A $\left.{ }^{1}\right]$ AAA-BP100; (F and I) NP-[Trz- $\beta$-A $\left.{ }^{34}\right]$-DD K.

$\mathrm{A}^{34}$ ]-DD K (Fig. 4h, j) [28]. These signals confirm the cycloaddition reaction between the alkyne-decorated peptides ([Pra]GAAA-BP100 and $\left.[\mathrm{Pra}] \mathrm{G}^{34}-\mathrm{DD} \mathrm{K}\right)$ and the azide-nanoparticles $\left(\mathrm{NP}-\mathrm{N}_{3}\right)$.

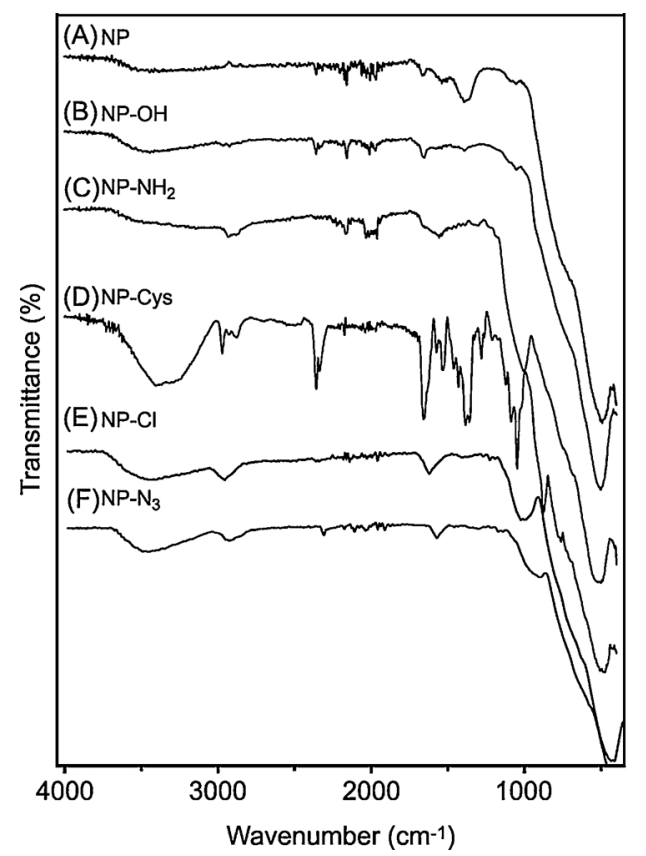

\subsection{Stability of the nanoparticles}

\subsubsection{Thermal analysis}

Thermogravimetric analysis of the $\gamma-\mathrm{Al}_{2} \mathrm{O}_{3}$ functionalized

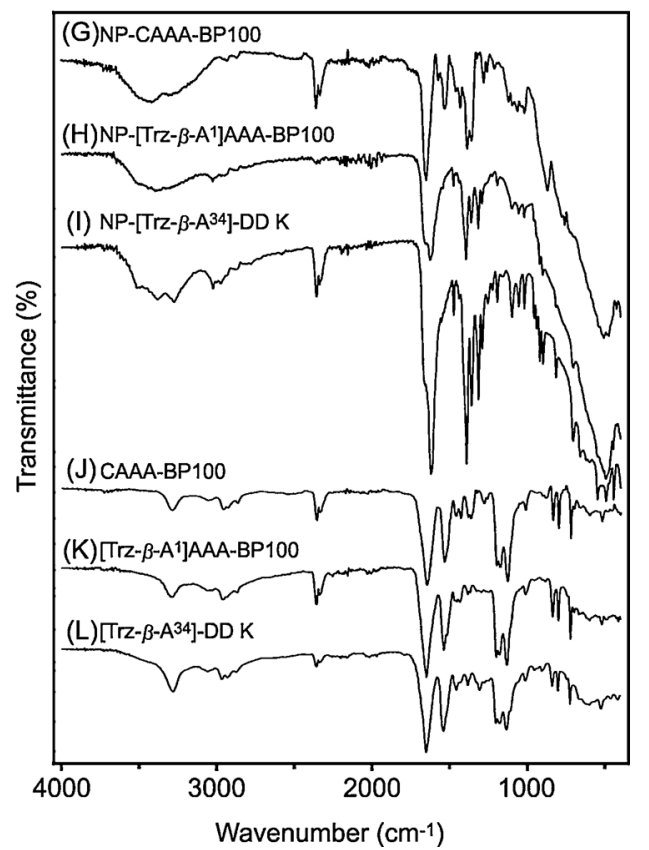

Fig. 3. FTIR. Left Panel: (A) NP, (B) NP-OH, (C) NP-NH 2 , (D) NP-Cys, (E) NP-Cl and (F) NP-N N $_{3}$ Right Panel: (G) NP-CAAA-BP100, (H) NP-[Trz- $\beta$-A ${ }^{1}$ ]-AAA-BP100, (I) NP-[Trz- $\left.\beta-A^{34}\right]$-DD K, (J) CAAA-BP100, (K) $\left[\right.$ Trz- $\left.\beta-A^{1}\right]$-AAA-BP100 and (L) $\left[\right.$ Trz- $\left.\beta-A^{34}\right]-D D$ K. 

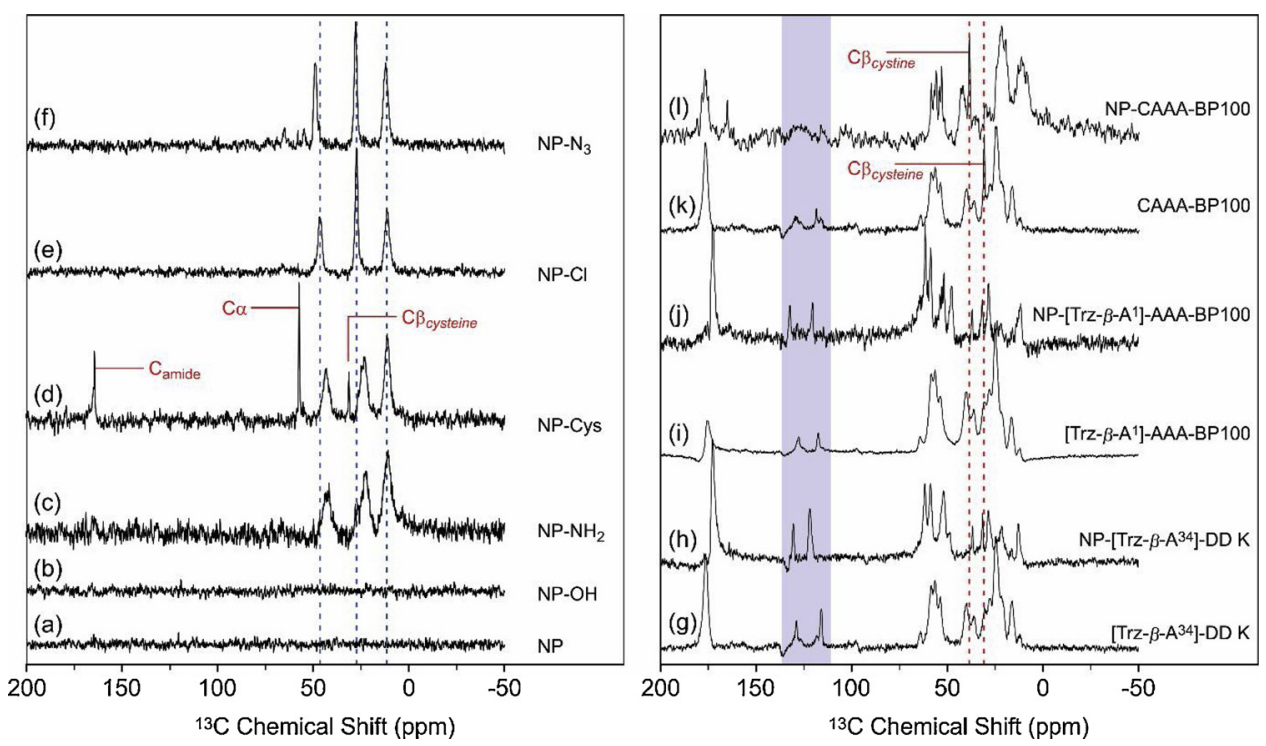

Fig. 4. ${ }^{13} \mathrm{C}$ solid-state NMR spectra. NP (a), NP-OH (b), NP-NH ${ }_{2}$ (c), NP-Cys (d), NP-Cl (e), NP-N $\mathrm{N}_{3}$ (f), [Trz- $\left.\beta-\mathrm{A}^{34}\right]-\mathrm{DD} \mathrm{K}(\mathrm{g}), \mathrm{NP}-\left[\mathrm{Trz}-\beta-\mathrm{A}^{34}\right]-\mathrm{DD} \mathrm{K}(\mathrm{h}),\left[\mathrm{Trz}-\beta-\mathrm{A}^{1}\right] \mathrm{AAA}-$ BP100 (i), NP-[Trz- $\left.\beta-A^{1}\right]$ AAA-BP100 (j), CAAA-BP100 (k) and NP-CAAA-BP100 (l).

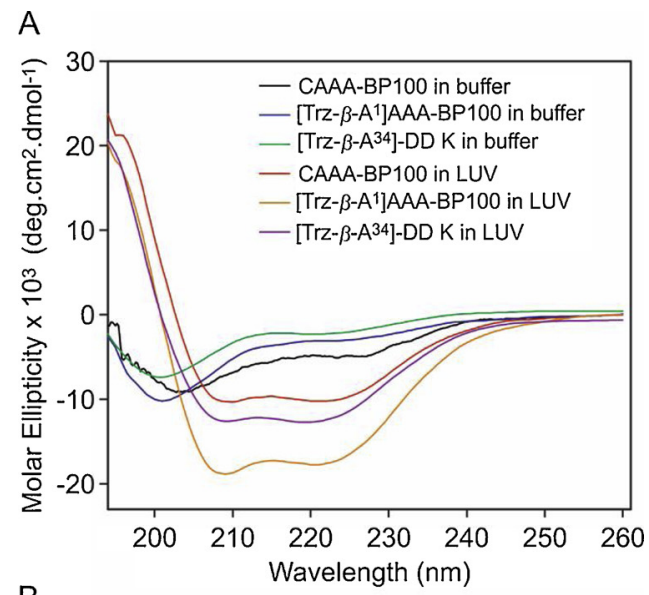

:

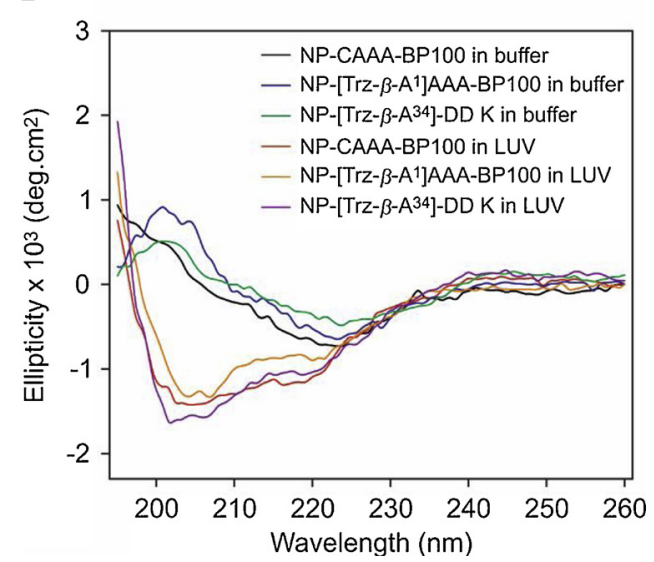

Fig. 5. CD spectra of (A) the free peptides and of the (B) peptide-decorated and triazole-peptide-decorated nanoparticles in presence of $10 \mathrm{mM}$ Tris- $\mathrm{HCl}$ buffer solution, pH 8.5, or 1.0 mM POPC:POPG (3:1) LUVs.

nanoparticles (Figure S4) clearly shows the presence of organic structures on the surface of the functionalized samples [15]. A well-defined mass loss (2-5\%) was observed around $380{ }^{\circ} \mathrm{C}$ for the samples $\mathrm{NP}-\mathrm{NH}_{2}$, NP-Cys and NP-CAAA. For the triazole-peptide-decorated nanoparticles, mass losses are even greater. In addition, an intermediate process around $250^{\circ} \mathrm{C}$ (Fig. S4D) is probably related to mass losses of the triazole rings, inasmuch as differential calorimetry experiments show that $1,2,3$-triazoles decompose in the range of $218-338^{\circ} \mathrm{C}$, starting with an exothermic phenomenon [29].

\subsubsection{Zeta potential ( $\zeta)$ measurements}

The electrophoretic mobility experiments for all nanoparticles were carried out to assess the chemical changes in their surfaces as result of the functionalization steps of both synthetic routes (Figure S5). Whereas the $\zeta$-potential values of NP and NP-OH (white bars) are near zero, the derivative forms obtained following the steps of route 1 for the synthesis of NP-CAAA-BP100 provided a large increase in zeta potential values (black bars). The presence of the aminopropyl group in $\mathrm{NP}-\mathrm{NH}_{2}$ and of the $\alpha$-amino termini in the NP-Cys raise the $\zeta$-potential values to +30.5 and +23.0 , respectively. Although with less magnitude, due the low substitution degree of peptide, an increase in the $\zeta$-potential value in comparison with $\mathrm{NP}-\mathrm{OH}$ was reached for NP-CAAA-BP100 $(+17.2)$ also, as the result of the presence of five Lys residues in the peptide chain [15].

Nanoparticles coming from subsequent functionalizations performed to obtain the triazole linked alumina-peptide nanoparticles (route 2) also led to major changes in the $\zeta$-potential values of the nanostructures, when compared to NP and $\mathrm{NP}-\mathrm{OH}$. Derivatizations with chloropropyl (NP-Cl) and azidopropyl (NP-N ${ }_{3}$ groups lead to extremely negative $\zeta$-potentials values (-13.8 and -16.4, respectively). Nevertheless, the immobilization of both peptide chains after cycloaddition reaction results in a marked increase of the $\zeta$-potential values for NP-[Trz- $\beta$-A $\left.{ }^{1}\right]$ AAA-BP100 ( $\Delta \zeta$ of $\left.13.1 \mathrm{mV}\right)$ and NP-[Trz- $\beta$-A $\left.{ }^{34}\right]$-DD K $(\Delta \zeta$ of $3.1 \mathrm{mV}$ ), mainly due to the presence of positively charged lysine residues.

\subsection{Biophysical investigations: membrane interactions of the NP-peptides and NP-triazole-peptides}

\subsubsection{Circular dichroism spectroscopy}

Secondary structural preferences of the free and nanoparticle-bound peptides and triazole-peptides were investigated in Tris - $\mathrm{HCl}$ buffer solutions, $\mathrm{pH} 8.5$, as well as in the presence of membrane-mimetic phospholipid vesicles by CD spectroscopy. The CD spectra recorded for all peptides and triazole-peptides in aqueous buffer solutions (Fig. 5A) showed a negative band at about $200 \mathrm{~nm}$, which is typical of peptides in random coil conformations. Higher degrees of helix formation are 
observed in the spectra of all free peptides in presence of POPC:POPG (3:1, molar ratio) LUV suspensions (Fig. S6). Even at $125 \mu \mathrm{M}$ of lipids, well-defined helical profiles are recognized in the spectra of the free species, since two clear minima are observed at 222 and $208 \mathrm{~nm}$, and a maximum point is observed at $193 \mathrm{~nm}$ A saturation plateau is reached at smaller lipid concentrations for CAAA-BP100 when compared to the triazole-peptides.

Contrary to the free peptides, the spectra of the peptide-alumina nanoparticles NP-CAAA-BP100; NP-[Trz- $\beta$ - $\left.A^{1}\right]$ AAA-BP100 and NP-[Trz$\beta$ - $\left.\mathrm{A}^{34}\right]$-DD K suspended in Tris $-\mathrm{HCl}$ buffer solutions (Fig. $5 \mathrm{~B}$ ) are indicative of $\beta$-sheet conformations, which are characterized by a positive band at about $200 \mathrm{~nm}$ and a negative band at $222 \mathrm{~nm}$. As observed for the free species, the nanoparticle-bound species also adopt $\alpha$-helical conformations in the presence of LUVs, confirming the interaction of the linked peptide chains in the nanostructures with the anionic phospholipid membranes [30].

\subsubsection{Surface plasmon resonance}

In order to investigate the membrane interactions of the alumina nanoparticle and its derivative forms we used SPR for investigating the affinity of the materials to POPC:POPG (3:1, molar ratio) LUVs immobilized on a $\mathrm{SiO}_{2}$ sensor chip in the presence of Tris $-\mathrm{HCl}$ running buffer, pH 8.5 (Fig. 6). The NP (black curves) present low-grade binding since the RU signal intensity virtually returns to the value observed for the lipid bilayers soon after injection time ( $45 \mathrm{~min}$ ) [31]. On the other hand, the sensograms for nanoparticles containing peptides exhibit high values of RU signal intensity even after completed the sample injections. Sensograms for free peptides were also obtained to compare the membrane interactions of the free and nanoparticle-bound peptides. Differences in the RU signal intensities are observed when the sensograms obtained for the free peptides (CAAABP100, [Trz- $\beta$ - $\left.\mathrm{A}^{1}\right] \mathrm{AAA}$ BP100, and $\left[\right.$ Trz- $\left.\beta-A^{34}\right]$-DD K, green curves in Fig. $\left.6 a-c\right)$ are compared to the ones obtained for the respective nanobiostructures (red, magenta and blue curves, in Fig. 6a-c, respectively), which suggests that peptide-nanoparticle bond may interfere on the strength of the peptidemembrane binding.

The sensograms recorded at different concentrations for the three alumina NP-peptides (Fig. S8) indicate that the amount of NP-peptide interacting with the lipids depends on the peptide concentration, until a saturation point is reached [32]. Although the concentration dependence of the sensograms and association constant $\left(K_{\mathrm{a}}\right)$ for NP-CAAABP100 or NP-[Trz- $\beta$-A $\left.{ }^{1}\right]$ AAA-BP100 binding (Fig. $6 \mathrm{~d}$ ) are similar to each other (6200 and $6900 \mathrm{M}^{-1}$, respectively), markedly higher response levels are noticed for the binding of the NP-[Trz- $\left.-\mathrm{A}^{34}\right]$-DD K, as a significantly greater association constant $\left(11,050 \mathrm{M}^{-1}\right)$ is observed (Table S2).

\subsection{Antimicrobial activities}

The antimicrobial activity of the synthesized peptide- and triazolepeptide-decorated nanostructures were investigated against three bacterial strains. In order to verify the antimicrobial potential of the organic and inorganic moieties, the activities of $\mathrm{NP}$ (in $\mathrm{g} \mathrm{L}^{-1}$ ), $\mathrm{NP}-\mathrm{OH}$ (in $\mathrm{g} \mathrm{L}^{-1}$ ), the respective peptide-modified nanostructures (in mmol L$L^{-1}$ and in $\mathrm{g} \mathrm{L}^{-1}$ ) and of the free peptide/triazole-peptides (in $\mathrm{mmol} \mathrm{L}^{-1}$ ) were also investigated and the results are presented in Fig. 7.

Whereas $\mathrm{NP}$ and $\mathrm{NP}-\mathrm{OH}$ show no antibacterial activity at the tested concentrations, these species show some antifungal potential. All of the investigated free peptides also show antibacterial and antifungal activities. Although no significant differences in the antibacterial activities of free BP100, CAAA-BP100 and [Trz- $\beta$ - $\left.A^{1}\right]$ AAA-BP100 are observed, $\left[\right.$ Trz- $\left.\beta-A^{34}\right]$-DD $K$ is less active than the wild-type peptide. Interestingly, whereas the binding of BP100 derivatives to the nanoparticles seems to keep its antimicrobial potential in comparison to the free peptides, the antimicrobial potential of $\left[\mathrm{Trz}-\beta-\mathrm{A}^{34}\right]-\mathrm{DD} \mathrm{K}$ is significantly improved after conjugation to the nanoparticle.

\section{Discussion}

The antimicrobial BP100 is a shorter-chain hybrid peptide composed of eleven residues (KKLFKKILKYL- $\mathrm{NH}_{2}$ ), which corresponds to the union of segments from Cecropin A and Melittin [33]. On the other hand, the antimicrobial peptide dermadistinctin K (DD K), originally isolated from the skin secretion of the anuran species Phyllomedusa distincta, is a long peptide-chain composed of 33 amino acid residues
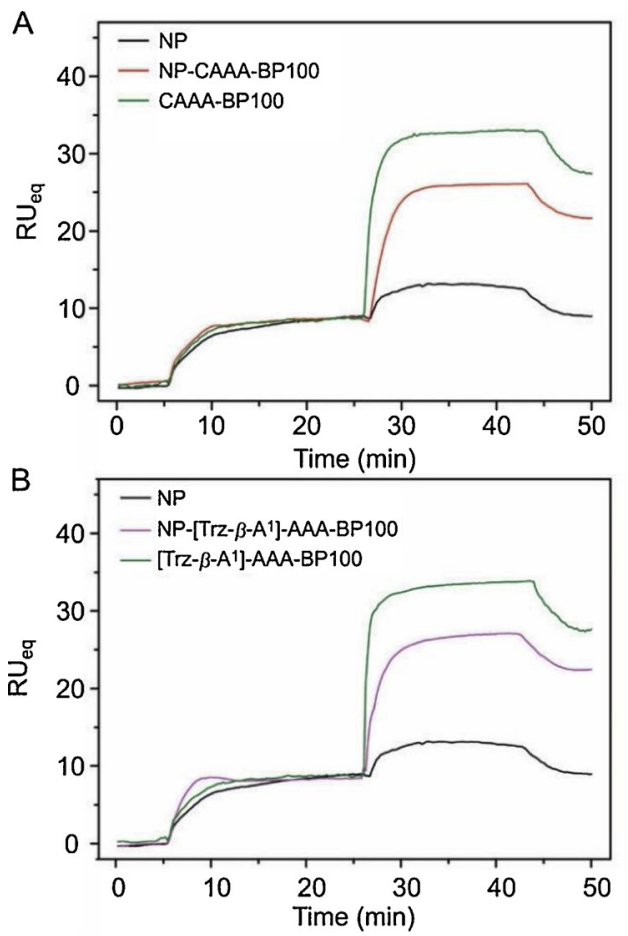
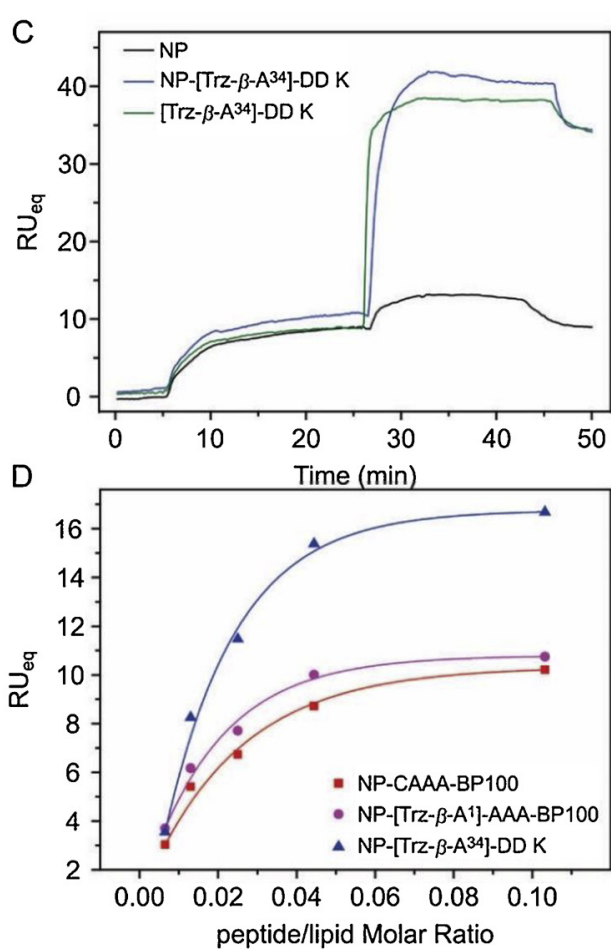

Fig. 6. Interactions between NP, its derived forms and free peptides measured by SPR. POPC:POPG (3:1) bilayers were immobilized onto the surface of a $\mathrm{SiO}_{2}$ sensor chip during 5 up to $25 \mathrm{~min}$ and the peptides were injected at $27 \mathrm{~min}$ in $10 \mathrm{mM}$ Tris- $\mathrm{HCl}$ buffer, $\mathrm{pH} 8.5$. Surface plasmon resonance sensograms for the bilayer interactions of CAAA-BP100 and NP derivatives forms of route synthesis of NPCAAA-BP100 (A), [Trz- $\left.\beta-A^{1}\right]$-AAA-BP100 and $\mathrm{NP}$ derivatives forms of synthesis route of NP$\left[\operatorname{Trz}-\beta-\mathrm{A}^{1}\right]$-AAA-BP100 (B), and $\left[\right.$ Trz- $\left.\beta-\mathrm{A}^{34}\right]$ DD $K$ and NP derivatives forms of synthesis route of NP-[Trz- $\left.\beta-A^{34}\right]-D D K(C)$. 


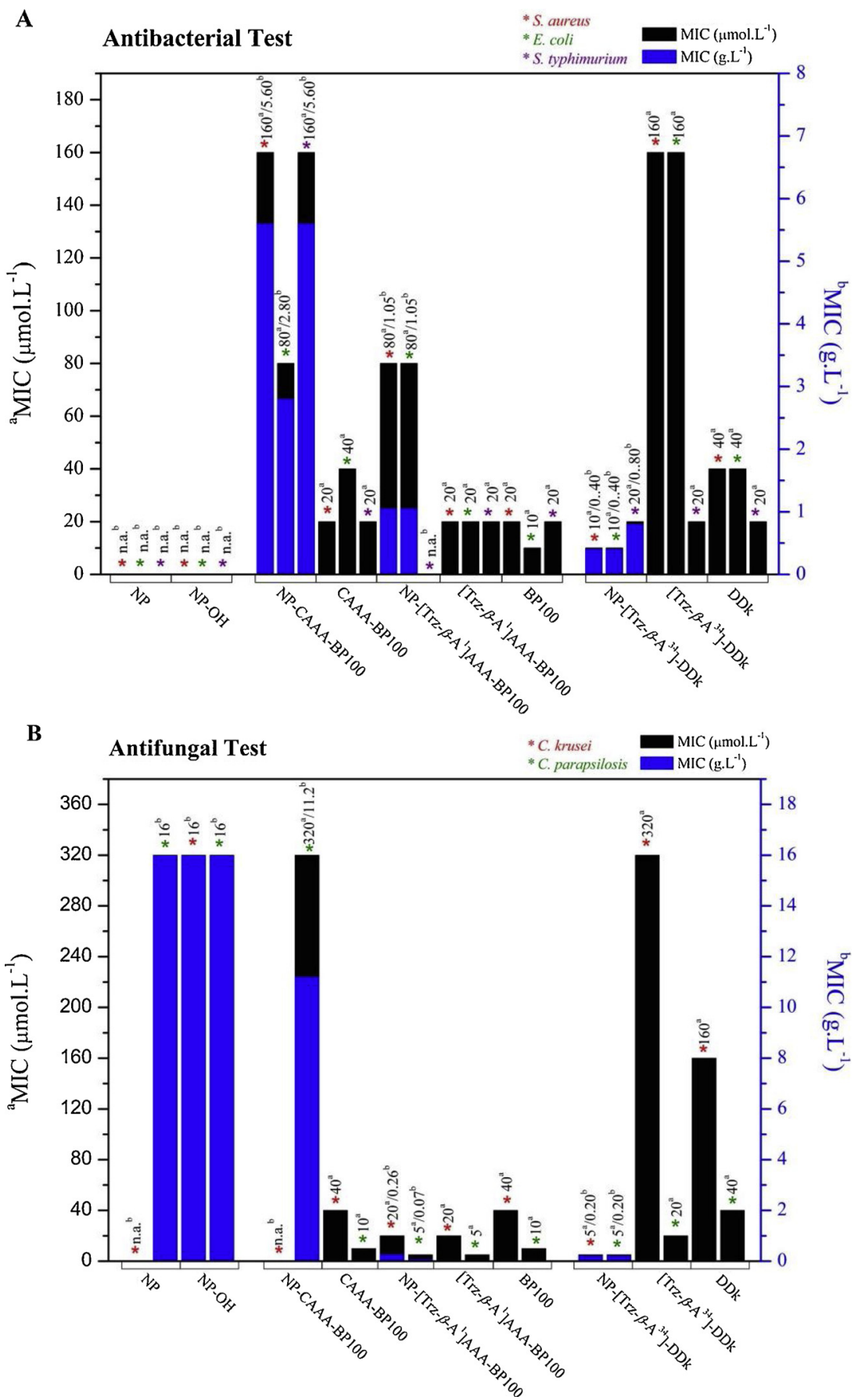

Fig. 7. Antimicrobial Activity of NPs, conjugated NPs-peptides and free peptides. (A) Bar graphs of antibacterial assays using $S$. aureus (red*), E. coli (green*) and $S$. typhimurium (magenta*) strains and (B) bar graphs of antifungal assays using C. krusei (red*) and C. parapziloziz (green*). The black bars correspond to MIC at $\mu \mathrm{mol.L} \mathrm{L}^{-1}$ and blue bars correspond to MIC in g.L $\mathrm{L}^{-1}$. n.a. showed no biological activity at the concentration tested. (For interpretation of the references to colour in this figure legend, the reader is referred to the web version of this article).

\section{(GLWSKIKAAGKEAAKAAAKAAGKAALNAVSEAV-NH ${ }_{2}$ ) [33-39].}

Previous structural and biophysical studies revealed that both DD $\mathrm{K}$ and BP100 exert their biological activities by interacting with bacterial membranes. CD and NMR spectroscopies showed that both peptides have random conformations in water, although they acquire $\alpha$-helical conformations in the presence of negatively charged membranes.Although both peptides show bilayer disruptive properties, the mechanisms of action depend on the bilayer composition and on the peptide-to-lipid ratios [38,40-42]. In this context, the analog peptides synthesized here were designed to prevent risks of activity loss. As BP100 is a relatively small peptide chain, composed of 11 amino acid residues, we decided to add a spacer of three alanine residues at the $\mathrm{N}$ termini of the two synthesized analogs to prevent disruption of the helicity after binding to the nanoparticles. CAAA-BP100 carries a cysteine residue, whereas [Pra]GAAA-BP100 carries a propargylglycine residue at the $N$-terminus to allow binding to the nanoparticles through disulfide bond and CuAAC reaction, respectively. Contrarily, the analog of $\mathrm{DD} \mathrm{K},[\mathrm{Pra}] \mathrm{G}^{34}$-DD $\mathrm{K}$ was designed only with an extra propargylglycine at the peptide C-terminus, since intrinsic fluorescence spectroscopy indicated that the Trp-3 residue is essential to anchor the peptide in the bilayer interface [40].

The NP-CAAA-BP100 nanobiostructure was obtained according to 
Route 1 (Fig. 1), i.e., via disulfide formation between previously prepared NP-Cys and the peptide CAAA-BP100. Interestingly, the functionalization degree to obtain NP-CAAA-BP100 was about ten times smaller than the degree to obtain NP-Cys. This result may be related to the competitive formation of undesired disulfide bonds, for example between cysteine derivatives immobilized on the nanoparticle surface, which reduces the number of available binding sites. In addition, there is the possibility of homodimer formation from the reaction between two CAAA-BP100 monomeric chains [25], which might reduce the amount of peptide available for binding to the NP-Cys. Two NP-triazolepeptides were obtained according to Route 2 (Fig. 1), i.e., via CuAAC reaction between azide-nanoparticles and two alkyne-decorated peptides. When the functionalization degrees to obtain the nanoparticles functionalized with BP100 derivatives through the two routes are compared to each other, a higher reaction yield is observed for route 2 . Therefore, from the synthesis point of view, the peptide binding from click chemistry gives higher reaction yields in comparison to the linkage via disulfide bond formation.

The morphology of the obtained materials (intermediates and nanobiostructures) were investigated by XRD, TEM and HRTEM. The functionalization with the peptides did not alter the significantly fibrous morphology of the nanostructures, as expected for the reactions performed with pre-prepared alumina nanoparticles. Nevertheless the peptide-decorated nanostructures, especially NP-[Trz- $\left.\beta-A^{34}\right]-D D$ K, presented a higher agglomeration degree, probably due to association of the 34-amino acid peptide chains. The linkage of the peptide structures to the nanoparticle surface was also confirmed by thermal analysis, as mass losses consistent with the decomposition of the peptide and triazole segments were observed. Structural information about the inorganic portion as well as general information about the organic functional groups were assessed by IR spectroscopy. In addition, the ${ }^{13} \mathrm{C}$ chemical shifts obtained from the ssNMR spectra allowed the detailed characterization of the functional groups within the organic portion of the nanobiomaterials, mainly the covalent bonds which connect the peptide chains with the organic portion of the derivative nanoparticles.

Several biophysical approaches were used to investigate the membrane-interactions of the obtained materials. In order to compare the effect of the peptide-nanoparticle conjugation to membrane-interactions, experiments were performed for the free peptides, alumina nanoparticles and peptide-decorated alumina nanoparticles.

CD spectroscopy indicated that the peptides and triazole-peptides adopt random coil conformations in aqueous environments, whereas membrane-active helical arrangements are observed in the presence of phospholipid vesicles. This is a quite common feature of linear antimicrobial peptides, which present well-defined structural arrangements after membrane binding [43]. Interestingly, the nanoparticle-bound species adopt $\beta$-sheet conformations in aqueous buffer. Since random coil conformations were observed for the free peptides in water, the $\beta$ conformations of the nanoparticle-bound peptides in aqueous buffer is an indicative of polypeptide interchain interactions within the nanostructure, as suggested by the TEM images. As observed for the free species, the nanoparticle-bound peptides adopt $\alpha$-helical conformations in the presence of phospholipid vesicles, which indicates that the peptides retain their membrane-active conformation regardless the presence of the nanoparticles.

The affinity of the nanobiostructures to anionic membranes was also investigated by SPR spectroscopy. The low-grade binding of the pure nanoparticles to the phospholipid vesicles indicate that the peptide moiety is responsible for the membrane association of the peptide-decorated nanoparticles. By comparing the RU signal intensities of the free peptides to the respective nanobiostructures, it becomes clear that the peptide-membrane interactions are less affected when a long peptide chain is linked to the nanosized structures in comparison to smaller peptide sequences. Whereas NP-CAAA-BP100 and NP-[Trz- $\beta$ - $\left.\mathrm{A}^{1}\right]$ AAABP100 sensograms revealed lower RU signal intensity when compared to CAAA-BP100 and $\left[\operatorname{Trz}-\beta-\mathrm{A}^{1}\right]$ AAA-BP100, respectively, NP-[Trz- $\beta-$
$\mathrm{A}^{34}$ ]-DD K presents slightly higher RU signal intensity in comparison to free $\left[\right.$ Trz- $\left.\beta-\mathrm{A}^{34}\right]$-DD K (Fig. $6 \mathrm{a}-\mathrm{c}$ ).

The association constants $\left(K_{\mathrm{a}}\right)$ of the interactions between the free peptides or peptide-nanostructures with the phospholipid vesicles were evaluated to better understand how the peptide-membrane interactions are related to their antimicrobial and antifungal activities. Markedly higher response levels are observed when the membrane-binding of the NP- $\left[\right.$ Trz- $\left.\beta-\mathrm{A}^{34}\right]$-DD $\mathrm{K}$ is compared to that of $\left[\mathrm{Trz}-\beta-\mathrm{A}^{1}\right] \mathrm{AAA}-\mathrm{BP} 100$, since the association constant of the longer-chain NP-triazole-peptide is about twice as high (Table S2) [44]. These results are in line with the $\mathrm{CD}$ experiments, since higher helicities are observed for the nanoparticles containing DD $\mathrm{K}$ than for nanoparticles containing BP100 (Fig. 5B). These results altogether confirm the greater membrane incorporation of the longer peptide chain when the two NP-triazolepeptides are compared to each other. Considering that the mechanisms of action of both BP100 and DD K depend on the in-plane alignment of the amphipathic helices on the bilayer surface $[38,41,42]$, our findings indicate that the chain length is important to retain the membrane disruptive properties of the peptides. The sensograms for the binding between either NP-CAAA-BP100 or NP-[Trz- $\left.\beta-\mathrm{A}^{1}\right]$ AAA-BP100 and the negative lipid bilayers are similar to each other, as the respective $K_{\mathrm{a}}$ values, confirming that the triazole ring does not increase the affinity of the NP-peptide to the membrane.

The antimicrobial activities of the synthesized peptide-decorated nanoparticles were investigated against three bacterial strains. When the activities of free BP100 and CAAA-BP100 are compared to each other, it is observed that the $N$-terminal extension only affects the activity against $E$. coli, which is reduced by a factor of four. These results suggest that the extra amino acid residues at the $N$-terminus of CAAABP100 generally do not alter the antimicrobial potential of the designed peptide. The triazole-derivative [Trz- $\beta$ - $\left.A^{1}\right]$ AAA-BP100 also show similar activities, confirming that the insertion of an azole ring does not alter the antibacterial activity of the peptide. In fact, neither the positive net charge was modified nor the extra four amino acid residues produce a sufficiently long structure to enable the transmembrane pore formation, which could modify the mechanism of action of BP100, already reported elsewhere [38]. Contrary to BP100 derivatives, DD K antibacterial potential was impaired by the triazole ring inserted at the peptide $C$-terminus, as [Trz- $\left.\beta-\mathrm{A}^{34}\right]$-DD K is less active than the wildtype peptide against two bacterial strains. ssNMR spectroscopy indicated that DD K adopts an in-plane alignment when reconstituted into phospholipid bilayers [41] and effects as partition of hydrophilic and hydrophobic residues among others are important to the peptidemembrane topology and activity [46]. The incorporation of the hydrophobic $\beta$-alanine-triazole residue (Trz- $\beta$-A) may alter the partition of hydrophilic and hydrophobic residues within the membrane surface and weakens peptide-membrane interactions as indeed confirmed by SPR measurements (see Fig. S8 and Table S2).

When the activity of free CAAA-BP100 is compared to the activities of the correspondent NP-peptide and NP-triazole-peptide higher MIC values are observed for the nanobiostrucures. A different profile was observed for the nanoparticle containing DD K, since NP-[Trz- $\left.\beta-A^{34}\right]$ DD K was significantly more active than the triazole-peptide ([Trz- $\beta$ $\left.\mathrm{A}^{34}\right]$-DD K) alone. Because BP100 and DD K peptides present distinct mechanisms of action $[38,41]$, the alumina nanoparticles seem to impair the action of CAAA-BP100, however they do not debilitate the potential of $\left[\right.$ Trz- $\left.\beta-A^{34}\right]$-DD K.

As regards the antifungal properties of the synthesized NP-peptide and NP-triazole-peptides, whereas the peptides BP100 and CAAABP100 presented the same MIC values against C. krusei and C. parapsilosis, the presence of the triazole ring enhanced the antifungal activity of $\left[\right.$ Trz- $\left.\beta-A^{1}\right]$ AAA-BP100. The antifungal properties related to the triazole ring are widely reported in literature [47,48], and its association to antimicrobial peptides has led to the increase of their antifungal potential $[45,49]$. In this case, the antifungal action is associated to the inhibition of ergosterol biosynthesis, an important fungi cell membrane 
component [50], rather than to membrane disruption effects, as the affinity to anionic membranes is not significantly modified by the presence of the triazole ring, as proved by SPR experiments with NP[Trz- $\beta$-A $\left.{ }^{1}\right]$ AAA-BP100 and NP- CAAA-BP100.

Although the binding of CAAA-BP100 to the nanostructures does not lead to an increase of activity, the association of triazole-DD $\mathrm{K}$ derivative to the nanoparticles [NP-[Trz- $\left.\beta-\mathrm{A}^{34}\right]$-DD K] clearly increases its antifungal potential. Therefore, it is very likely that the longer peptide chain of DD $\mathrm{K}$ ensures an adequate spacing and the nanoparticle-bound peptide retains membrane disruptive properties similar to those of the wild-type sequence. As a result, NP-[Trz- $\left.\beta-\mathrm{A}^{34}\right]-\mathrm{DD} \mathrm{K}$ ignites higher disruption in the microbial membrane and consequently higher activity is observed for the nanoparticle containing the longer peptide chain [51]. Furthermore, this higher antimicrobial activity can be associated to the increase of the local concentration of peptide chains on the bilayer surface, since these organic molecules are agglomerated $\left(0.02 \mathrm{~g} \cdot \mathrm{mol}^{-1}\right)$ on the nanoparticle surface. Strong membrane-disruptive properties associated to intracellular effects have already been reported for alumina nanoparticles acting on Candida yeasts [52]. In addition, mesoporous alumina inhibits the growth of the phytopathogen Fusarium oxysporium in vitro and in infected tomato plants [53]. The material obtained by Jalal and co-workers was active on several Candida species and HRTEM revealed that the nanoparticle anchoring occurs on the cell surface and that subsequent internalization of minor nanostructures in the yeast cells leads to the rupture of the wall and cell membranes and, consequently, to cell death.

\section{Conclusion}

Two novel synthetic approaches to incorporate peptides in alumina nanoparticles were presented. Antimicrobial sequences were covalently bound to the nanoparticles either through disulfide bond formation or through the copper(I)-catalyzed azide alkyne cycloaddition (CuAAC) reaction, which resulted in the linkage of the peptides to the nanoparticles via a dimeric cystine residue or via a 1,4-disubstituted 1,2,3triazole ring. Although alumina NP and its derivative forms presented similar nanofiber structures, triazole-peptide-decorated nanoparticles and the higher aggregation level is related to interactions between the peptide chains. The triazole-peptide-nanoparticles have significantly stronger antifungal activities in comparison with the peptide-nanoparticles, which is certainly related to the combined action of the peptide and triazole moieties. Interestingly, SPR spectroscopy shows that the triazole ring does not increase the association constant of the nanoparticle-triazole-peptides to mimetic membranes, which indicates that the stronger antifungal potential of the triazole-peptide-nanoparticles is related to the well-known effects of the azoles on the inhibition of ergosterol biosynthesis. By allying the antibacterial and antifungal potentials of antimicrobial peptides/triazole-peptides to the well-known advantages of nanostructured alumina, the synthetic methodologies proposed here open new possibilities for the development of promising biomaterials. One important point to be addressed is how to apply these nanomaterials associated to polymeric supports for use in orthopedic or orthodontic implants, in order to increase tissue regeneration while at the same time preventing rejection caused by microbial infections.

\section{Acknowledgements}

LMFCT acknowledges a grant from CAPES. NAB and IPG acknowledge grants from FAPEMIG. TLS acknowledges a grant from PNPD/ CAPES. JMR and JPM acknowledge grants from CNPq. This work was partially supported by Rede Agronano, Embrapa. This work is a collaboration research project of members of the Rede Mineira de Química (RQ-MG). We also acknowledge financial support from $\mathrm{CNPq}$, FAPEMIG, FAPEG, CAPES, PRPq-UFMG and PRPPG-UFVJM.

\section{Appendix A. Supplementary data}

Supplementary material related to this article can be found, in the online version, at doi:https://doi.org/10.1016/j.colsurfb.2019.01.052.

\section{References}

[1] M. Jena, S. Mishra, S. Jena, S.S. Mishra, Nanotechnology-future prospect in recent medicine: a review, Int. J. Basic Clin. Pharmacol. 2 (2017) 353-359.

[2] I.Y. Wong, S.N. Bhatia, M. Toner, Nanotechnology: emerging tools for biology and medicine, Genes Dev. 27 (2013) 2397-2408.

[3] C. Burda, X. Chen, R. Narayanan, M.A. El-Sayed, Chemistry and properties of nanocrystals of different shapes, Chem. Rev. 105 (2005) 1025-1102.

[4] Y. Li, Y. Wang, S.-H. Ou, L.L. Lock, X. Xu, S. Ghose, Z.J. Li, H. Cui, Conformation preservation of $\alpha$-Helical peptides within supramolecular filamentous assemblies, Biomacromolecules 18 (2017) 3611-3620.

[5] G.R. Rudramurthy, M.K. Swamy, U.R. Sinniah, A. Ghasemzadeh, Nanoparticles: alternatives against drug-resistant pathogenic microbes, Molecules 21 (2016) 836.

[6] E.E.L. Swan, K.C. Popat, T.A. Desai, Peptide-immobilized nanoporous alumina membranes for enhanced osteoblast adhesion, Biomaterials 26 (2005) 1969-1976.

[7] I.M. Hamouda, Current perspectives of nanoparticles in medical and dental biomaterials, J. Biomed. Res. 26 (2012) 143.

[8] M.J. Kogan, I. Olmedo, L. Hosta, A.R. Guerrero, L.J. Cruz, F. Albericio, Peptides and metallic nanoparticles for biomedical applications, Nanomedicine (Lond) (2007).

[9] L.G. Gutwein, T.J. Webster, Osteoblast and chrondrocyte proliferation in the presence of alumina and titania nanoparticles, J. Nanopart. Res. 4 (2002) 231-238.

[10] R.L. Price, L.G. Gutwein, L. Kaledin, F. Tepper, T.J. Webster, Osteoblast function on nanophase alumina materials: influence of chemistry, phase, and topography, J. Biomed. Mater. Res. A 67 (2003) 1284-1293.

[11] R. Price, K. Haberstroh, T. Webster, Enhanced functions of osteoblasts on nanos tructured surfaces of carbon and alumina, Med. Biol. Eng. Comput. 41 (2003) $372-375$.

[12] M. Ribeiro, F.J. Monteiro, M.P. Ferraz, Infection of orthopedic implants with emphasis on bacterial adhesion process and techniques used in studying bacterialmaterial interactions, Biomatter 2 (2012) 176-194.

[13] J. Ageitos, A. Sánchez-Pérez, P. Calo-Mata, T. Villa, Antimicrobial peptides (AMPs): ancient compounds that represent novel weapons in the fight against bacteria, Biochem. Pharmacol. 133 (2017) 117-138.

[14] S.S. Athari, Z. Pourpak, G. Folkerts, J. Garssen, M. Moin, I.M. Adcock, M. Movassaghi, M.S. Ardestani, S.M. Moazzeni, E. Mortaz, Conjugated AlphaAlumina nanoparticle with vasoactive intestinal peptide as a Nano-drug in treatment of allergic asthma in mice, Eur. J. Pharmacol. 791 (2016) 811-820.

[15] L. Torres, N. Braga, I. Gomes, M. Almeida, T. Santos, J. de Mesquita, L. da Silva, H. Martins, K. Kato, W. Dos Santos, Nanobiostructure of fibrous-like alumina functionalized with an analog of the BP100 peptide: synthesis, characterization and biological applications, Colloids Surf. B Biointerfaces 163 (2018) 275-283.

[16] P. Appendini, J.H. Hotchkiss, Review of antimicrobial food packaging, Innov. Food Sci. Emerg. Technol. 3 (2002) 113-126.

[17] X. Wu, P.-H. Wei, X. Zhu, M.J. Wirth, A. Bhunia, G. Narsimhan, Effect of immobilization on the antimicrobial activity of a cysteine-terminated antimicrobial Peptide Cecropin P1 tethered to silica nanoparticle against E. Coli O157: H7 EDL933, Colloids Surf. B Biointerfaces 156 (2017) 305-312.

[18] M.K. Kathiravan, A.B. Salake, A.S. Chothe, P.B. Dudhe, R.P. Watode, M.S. Mukta, S. Gadhwe, The biology and chemistry of antifungal agents: a review, Biorg. Med. Chem. 20 (2012) 5678-5698.

[19] W.C. Chan, P.D. White, Fmoc Solid Phase Peptide Synthesis, Oxford University Press, 2000.

[20] H. Potdar, K.-W. Jun, J.W. Bae, S.-M. Kim, Y.-J. Lee, Synthesis of nano-sized porous $\gamma$-alumina powder via a precipitation/digestion route, Appl. Catal. A Gen. 321 (2007) 109-116.

[21] V. Pakharukova, D. Yatsenko, E.Y. Gerasimov, A. Shalygin, O. Martyanov, S. Tsybulya, Coherent 3D nanostructure of $\gamma$-Al2O3: simulation of whole X-ray powder diffraction pattern, J. Solid State Chem. 246 (2017) 284-292.

[22] Y. Cai, H. Huang, L. Wang, X. Zhang, Y. Yuan, R. Li, H. Wan, G. Guan, Facile synthesis of pure phase $\gamma$-AlOOH and $\gamma$-Al 2 O 3 nanofibers in a recoverable ionic liquid via a low temperature route, RSC Adv. 5 (2015) 104884-104890.

[23] S. Liu, C. Chen, Q. Liu, Y. Zhuo, D. Yuan, Z. Dai, J. Bao, Two-dimensional porous $\gamma$ $\mathrm{AlOOH}$ and $\gamma$-Al 2 O 3 nanosheets: hydrothermal synthesis, formation mechanism and catalytic performance, RSC Adv. 5 (2015) 71728-71734.

[24] V.K. Gupta, S. Agarwal, T.A. Saleh, Synthesis and characterization of aluminacoated carbon nanotubes and their application for lead removal, J. Hazard. Mater. 185 (2011) 17-23.

[25] R.M. Verly, J.M. Resende, E.F. Junior, M.T. De Magalhães, C.F. Guimarães, V.H. Munhoz, M.P. Bemquerer, F.C. Almeida, M.M. Santoro, D. Piló-Veloso, Structure and membrane interactions of the homodimeric antibiotic peptide homotarsinin, Sci. Rep. 7 (2017) 40854.

[26] D. Sharma, K. Rajarathnam, 13C NMR chemical shifts can predict disulfide bond formation, J. Biomol. NMR 18 (2000) 165-171.

[27] O.A. Martin, M.E. Villegas, J.A. Vila, H.A. Scheraga, Analysis of ${ }^{13} \mathrm{C}^{\alpha}$ and ${ }^{13} \mathrm{C}^{\beta}$ chemical shifts of cysteine and cystine residues in proteins: a quantum chemical approach, J. Biomol. NMR 46 (2010) 217-225.

[28] X.W. Sun, P.F. Xu, Z.Y. Zhang, 1H and 13C NMR spectroscopy of substituted 1, 2, 3-triazoles, Magn. Reson. Chem. 36 (1998) 459-460.

[29] A.R. Katritzky, Z. Wang, M. Tsikolisa, C.D. Hall, M. Carman, Benzotriazole is 
thermally more stable than 1, 2, 3-triazole, Tetrahedron Lett. 47 (2006) 7653-7654.

[30] S.M. Kelly, T.J. Jess, N.C. Price, How to study proteins by circular dichroism, Biochimica et Biophysica Acta (BBA)-Proteins and Proteomics 1751 (2005) 119-139.

[31] K. Hall, H. Mozsolits, M.-I. Aguilar, Surface plasmon resonance analysis of antimicrobial peptide-membrane interactions: affinity \& mechanism of action, Lett. Pept. Sci. 10 (2003) 475-485.

[32] N. Papo, Y. Shai, Exploring peptide membrane interaction using surface plasmon resonance: differentiation between pore formation versus membrane disruption by lytic peptides, Biochemistry 42 (2003) 458-466.

[33] E. Badosa, R. Ferre, M. Planas, L. Feliu, E. Besalú, J. Cabrefiga, E. Bardají, E. Montesinos, A library of linear undecapeptides with bactericidal activity against phytopathogenic bacteria, Peptides 28 (2007) 2276-228s5.

[34] C. Batista, L.R. da Silva, A. Sebben, A. Scaloni, L. Ferrara, G. Paiva, T. Olamendi-Portugal, L. Possani, C. Bloch Jr, Antimicrobial peptides from the Brazilian frog Phyllomedusa distincta1, Peptides 20 (1999) 679-686.

[35] R.M. Verly, M.A. Rodrigues, K.R.P. Daghastanli, A.M.L. Denadai, I.M. Cuccovia, C. Bloch Jr, F. Frézard, M.M. Santoro, D. Piló-Veloso, M.P. Bemquerer, Effect of cholesterol on the interaction of the amphibian antimicrobial peptide DD K with liposomes, Peptides 29 (2008) 15-24.

[36] R. Ferre, E. Badosa, L. Feliu, M. Planas, E. Montesinos, E. Bardají, Inhibition of plant-pathogenic bacteria by short synthetic cecropin A-melittin hybrid peptides, Appl. Environ. Microbiol. 72 (2006) 3302-3308.

[37] R. Ferre, M.N. Melo, A.D. Correia, L. Feliu, E. Bardaji, M. Planas, M. Castanho, Synergistic effects of the membrane actions of cecropin-melittin antimicrobial hybrid peptide BP100, Biophys. J. 96 (2009) 1815-1827.

[38] M.C. Manzini, K.R. Perez, K.A. Riske, J.C. Bozelli Jr., T.L. Santos, M.A. da Silva, G.K. Saraiva, M.J. Politi, A.P. Valente, F.C. Almeida, H. Chaimovich, M.A. Rodrigues, M.P. Bemquerer, S. Schreier, I.M. Cuccovia, Peptide:lipid ratio and membrane surface charge determine the mechanism of action of the antimicrobial peptide BP100, Conformational and functional studies, Biochim. Biophys. Acta 1838 (2014) 1985-1999.

[39] J. Cabrefiga, E. Montesinos, Lysozyme enhances the bactericidal effect of BP100 peptide against Erwinia amylovora, the causal agent of fire blight of rosaceous plants, BMC Microbiol. 17 (2017) 39.

[40] R.M. Verly, M.A. Rodrigues, K.R.P. Daghastanli, A.M.L. Denadai, I.M. Cuccovia, C. Bloch, F. Frézard, M.M. Santoro, D. Piló-Veloso, M.P. Bemquerer, Effect of cholesterol on the interaction of the amphibian antimicrobial peptide DD K with liposomes, Peptides 29 (2008) 15-24.

[41] R.M. Verly, C.M. Moraes, J.M. Resende, C. Aisenbrey, M.P. Bemquerer, D. PilóVeloso, A.P. Valente, F.C.L. Almeida, B. Bechinger, Structure and membrane interactions of the antibiotic peptide dermadistinctin $\mathrm{K}$ by multidimensional solution and oriented 15N and 31P solid-state NMR spectroscopy, Biophys. J. 96 (2009) 2194-2203.

[42] H. Zamora-Carreras, E. Strandberg, P. Muhlhauser, J. Burck, P. Wadhwani, M.A. Jimenez, M. Bruix, A.S. Ulrich, Alanine scan and (2)H NMR analysis of the membrane-active peptide BP100 point to a distinct carpet mechanism of action, Biochim. Biophys. Acta 1858 (2016) 1328-1338.

[43] K.A.G. Gusmao, D.M. Dos Santos, V.M. Santos, M.E. Cortes, P.V.M. Reis, V.L. Santos, D. Pilo-Veloso, R.M. Verly, M.E. de Lima, J.M. Resende, Ocellatin peptides from the skin secretion of the South American frog Leptodactylus labyrinthicus

(Leptodactylidae): characterization, antimicrobial activities and membrane interactions, J. Venom. Anim. Toxins Incl. Trop. Dis. 23 (2017) 4.

[44] H. Mozsolits, H.J. Wirth, J. Werkmeister, M.I. Aguilar, Analysis of antimicrobial peptide interactions with hybrid bilayer membrane systems using surface plasmon resonance, Biochim. Biophys. Acta 1512 (2001) 64-76.

[45] E.F. Junior, C.F. Guimarães, L.L. Franco, R.J. Alves, K.C. Kato, H.R. Martins, J.D. de Souza Filho, M.P. Bemquerer, V.H. Munhoz, J.M. Resende, Glycotriazole-peptides derived from the peptide HSP1: synergistic effect of triazole and saccharide rings on the antifungal activity, Amino Acids 49 (2017) 1389-1400.

[46] J.M. Resende, R.M. Verly, C. Aisenbrey, A. Cesar, P. Bertani, D. Pilo-Veloso, B. Bechinger, Membrane interactions of phylloseptin-1, -2 , and -3 peptides by oriented solid-state NMR spectroscopy, Biophys. J. 107 (2014) 901-911.

[47] D. Dheer, V. Singh, R. Shankar, Medicinal attributes of 1,2,3-triazoles: current developments, Bioorg. Chem. 71 (2017) 30-54.

[48] H.-Z. Zhang, J.-J. Wei, K.V. Kumar, S. Rasheed, C.-H. Zhou, Synthesis and biological evaluation of novel d-glucose-derived 1, 2, 3-triazoles as potential antibacterial and antifungal agents, Med. Chem. Res. 24 (2015) 182-196.

[49] S.Z. Ferreira, H.C. Carneiro, H.A. Lara, R.B. Alves, J.M. Resende, H.M. Oliveira, L.M. Silva, D.A. Santos, R.P. Freitas, Synthesis of a new peptide-coumarin conjugate: a potential agent against cryptococcosis, ACS Med. Chem. Lett. 6 (2015) $271-275$.

[50] M. Rautenbach, A.M. Troskie, J.A. Vosloo, Antifungal peptides: to be or not to be membrane active, Biochimie 130 (2016) 132-145.

[51] N. Papo, Y. Shai, Can we predict biological activity of antimicrobial peptides from their interactions with model phospholipid membranes? Peptides 24 (2003) 1693.

[52] M. Jalal, M.A. Ansari, A.K. Shukla, S.G. Ali, H.M. Khan, R. Pal, J. Alam, S.S. Cameotra, Green synthesis and antifungal activity of Al 2 O 3 NPs against fluconazole-resistant Candida spp isolated from a tertiary care hospital, RSC Adv. 6 (2016) 107577-107590.

[53] M. Shenashen, A. Derbalah, A. Hamza, A. Mohamed, S. El Safty, Antifungal activity of fabricated mesoporous alumina nanoparticles against root rot disease of tomato caused by Fusarium oxysporium, Pest Manag. Sci. 73 (2017) 1121-1126. 